\title{
Use of low intensity laser treatment in neuropathic pain refractory to clinical treatment in amputation stumps
}

This article was published in the following Dove Press journal:

International Journal of General Medicine

4 September 2012

Number of times this article has been viewed

\author{
Eduardo Santamaria \\ Carvalhal Ribas \\ Wellingson Silva Paiva \\ Natali Cordeiro Pinto \\ Lin Tchia Yeng \\ Massako Okada \\ Erich Talamoni Fonoff \\ Maria Cristina Chavantes \\ Manoel Jacobsen Teixeira \\ Pain Center, Department of \\ Neurology, Hospital das Clínicas \\ School of Medicine, University \\ of São Paulo, Brazil
}

\begin{abstract}
Debilitating stump pain following amputation surgery is a major problem when it affects the patient's quality of life, often making the patient totally dependent on others for their day-to-day care. Attempts have been made to treat those patients through pharmacological, psychological, and physical therapies, but in many cases these fail to relieve the pain. This article focuses on three patients with chronic, intense, and debilitating stump pain who were previously treated with pain medications, but with little success. These patients underwent nine sessions of low-intensity laser therapy (LILT) to the stump - this is a new treatment that has been used to treat other pain disorders. All patients reported a decrease in the intensity of their pain and increased ability to perform daily living activities during a 4-month follow-up.
\end{abstract}

Keywords: pain, laser therapy, amputation stumps

\section{Introduction}

There are an estimated 150,000 surgical amputations per year in the US, most of which are secondary in nature, arising from diabetes mellitus, vascular disease, trauma, and cancer. ${ }^{1}$ Residual pain in amputation stumps can extend beyond the normal recovery time, and is seen in $13 \%-71 \%$ of cases. ${ }^{2,3}$ After the nerve injury, spontaneous nerve activity develops at the site of injury and the corresponding dorsal root ganglia. These changes are followed by sensitization, reduction of the pain threshold, exaggerated response to nociceptive stimuli (hyperalgesia) or non-nociceptive (alodinea), and phantom sensations. ${ }^{4}$ The syndrome of a phantom limb with associated pain is found in $70 \%-85 \%$ of amputees, and pain persists in $5 \%-10 \%$ of these people. ${ }^{3,5}$ Sensory abnormalities are also described in more than $50 \%$ of patients with amputation stumps. ${ }^{6}$

In a study of 96 upper limb amputees, Schley et $\mathrm{al}^{7}$ found that $44.6 \%$ of patients suffered from phantom pain, $53.8 \%$ had phantom sensations, $61.5 \%$ had stump pain, and $78.5 \%$ had stump sensation. The authors reported that stump pain gradually decreased in $19(47.5 \%)$ of 40 amputees in the first year following amputation, but was stable in $12(30 \%)$ patients, and some may present with severe stump pain that is resistant to treatment.

The residual pain may be due to several factors, such as an underlying disease, bone deformities, wound healing, or neuropathic pain. ${ }^{3}$ Many treatments have been reported for pain in a stump following amputation, and these can be divided into three categories: pharmacological, psychological, and physical. The first includes the use of anti-inflammatory drugs, opioids, anti-depressants, and anti-convulsion drugs, in addition to the use of injections of steroids, analgesic nerve blocks, and
Correspondence: Wellingson Silva Paiva Eneas Aguiar 255 Office 4080 Zip code 054030 I0, São Paulo, Brazil Tel +55 I I 25486900

Fax +55 II 25486906

Email wellingsonpaiva@hotmail.com 
painkiller adhesives. ${ }^{7,8}$ The second is represented mainly by antidepressant therapy, and the third included transcutaneous electrical stimulation of nerves, spinal electrical stimulation, low-intensity laser therapy, rehabilitation exercises and massage, and surgery. ${ }^{9-11}$

The use of low-intensity laser therapy (LILT) started in Europe and Russia in the 1960s. LILT - also known as photobiology or biostimulation - makes use of low levels of radiation, with the use of a single wavelength. ${ }^{12,13}$ It is suggested that the biological effect of this therapy is secondary to the direct effects of the light radiation, and not the result of thermal processes. ${ }^{14}$

Clinically, there have been many uses of LILT demonstrated, but most require further studies before conclusions can be drawn. It is proposed that LILT accelerates recovery after trauma. One study indicated that tensor strength of wounds increased considerably after 1-2 weeks of laser treatment, with this improvement associated with a significant increase in collagen after 2 weeks of treatment. ${ }^{15}$ The effects of LILT on the peripheral nervous system are also encouraging. When treated with transcutaneous LILT, rats with facial nerve injuries caused by crushing had an increased rate of nerve regeneration..$^{16}$ In a double-blind controlled study, LILT and transcutaneous electrical stimulation were associated with a significant reduction of subjective pain and improved sensory latency in patients with carpal tunnel syndrome. ${ }^{17}$ Patients with maxillofacial pain including trigeminal neuralgia also reported decreased pain in response to laser therapy. ${ }^{18}$

It is unclear how LILT promotes an analgesic effect. In the case of neuropathic pain, LILT may affect the release of neurotransmitters such as serotonin, ${ }^{19}$ increase production of mitochondrial ATP, ${ }^{20}$ increase the release of endorphins, ${ }^{21}$ and have anti-inflammatory effects..$^{22}$ In controlled laboratory studies it has been shown that LILT may reduce inflammation by lowering the levels of prostaglandin PGE2 and inhibiting cyclo-oxygenase -2 (COX -2) in cell cultures..$^{23-26}$

\section{Materials and methods}

Three patients with neuropathic pain in an amputation stump were selected in the pain clinic of our hospital. All patients experienced significant neuropathic pain in the form of the sensation of shock or needles on the scar of the amputation stump - in all cases, this pain was represented by high scores on the visual analog scale (VAS) of pain, and the pain persisted despite analgesics or functional rehabilitation. The patients also had functional limitations in the activities they could perform as a result of this pain. We selected three patients with higher pain intensity (VAS $>8$ ), pain that did not respond to medical treatment, homogeneity of previous treatment (the patients were treated with the same medications and rehabilitation), and all three patients had undergone their traumatic amputation over 1 year prior to this study.

These patients were evaluated in a medical interview prior to LILT application. Three assessments were made of each patient. The first of these was the pain VAS, which consists of a horizontal line ten centimeters long with "No pain" and "Pain as bad as it could be" marked on the left and right ends of the line, respectively. The patients were required to make a mark on the line indicating how bad the pain was in their amputation stump, and the distance from the left end to the mark on the scale was measured and recorded as the VAS score. The second assessment was the Barthel scale, which aims to quantify the patient's ability to carry out daily living activities such as eating or using a toilet, and ranges from the highest dependency ( 0 points) to the highest independency (100 points). ${ }^{27}$ The third assessment, the Lawton scale, quantifies impairment to the carrying out of daily tasks and ranges from the highest dependency ( 8 points) to the highest independency ( 24 points). ${ }^{28}$

After assessment, patients received nine sessions (three treatment sessions per week for three weeks, as reported by Lam and Cheing) ${ }^{29}$ of low-intensity laser (laser diode, $\lambda=830 \mathrm{~nm}$, dose ranging from $8-15 \mathrm{~J} / \mathrm{cm}^{2}, \mathrm{P}=70 \mathrm{~mW}$ ) on the amputation stump scar. A continuous wave diode laser was used (DMC, São Paulo, Brazil). Following treatment, the patients were re-evaluated using the three scales described above, and patients were monitored for 4 months. No side effects were observed in response to the LILT.

This project was analyzed and approved by the Ethics Committee of our institution (Research Protocol \# 01254/09).

The main objective of the study was to assess whether this treatment would result in pain relief in the amputated stump, expressed by a decrease in VAS scores. As a secondary objective of the study, the effect of LILT on the improvement of independency and functionality of the patient was also assessed (this would be expressed by an increase in the Barthel and Lawton scales).

\section{Results}

All three patients reported subjective pain relief after nine sessions of low-intensity laser. The patients had allodynia and hyperpathia prior to treatment, and the LILT treatment produced a verified remission in hyperpathia and 
significant control of allodynia. The patients' post-treatment reporting of pain through the VAS also showed a significant reduction in pain in all three cases, as shown in Figure 1, with pain dropping by five to seven points.

The functionality and independence of the patients were also significantly improved - measured on the Barthel scale, improvements of 45 to 55 points were seen, and in the Lawton scale the improvements ranged from eight to ten points (Figure 2).

\section{Discussion}

The application of low-intensity laser treatment contributed to an improvement in our patients' reported pain intensity, their ability to carry out daily living activities (Barthel scale), and their impairment in the carrying out of daily tasks (Lawton scale).

Reported pain was reduced by the LILT treatment, with $50 \%-70 \%$ less pain after nine sessions. This improvement should be interpreted with caution since all of the patients studied had high scores of pain intensity on the VAS before treatment, and the same outcome should not be expected in patients who begin treatment with lower intensities of pain. Also, the study group is small, and the results should be seen only as a descriptive study of a new tool.

Although the exact mechanism is unknown, LILT has been beneficial in many studies that have used a range of different pain models. Generally these studies do not show a good evidence level due to a lack of randomization, doubleblind design, or the use of a placebo group. ${ }^{30}$

A reduction in pain without the use of analgesic drugs can help reduce the excessive use of medication, reducing the potential side effects of high doses. Since no side effects were observed in the use of LILT, its use can probably be started at a very early stage and on patients suffering from less pain.

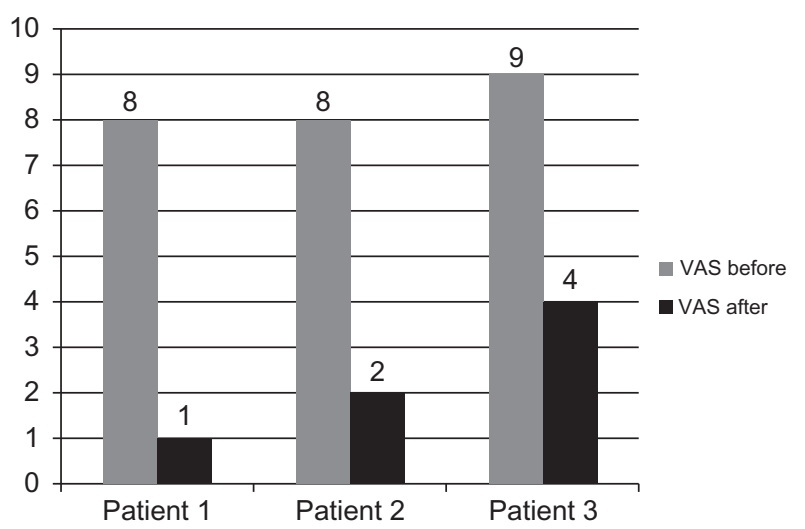

Figure I Analysis of visual analog scale before and after low-intensity laser therapy.

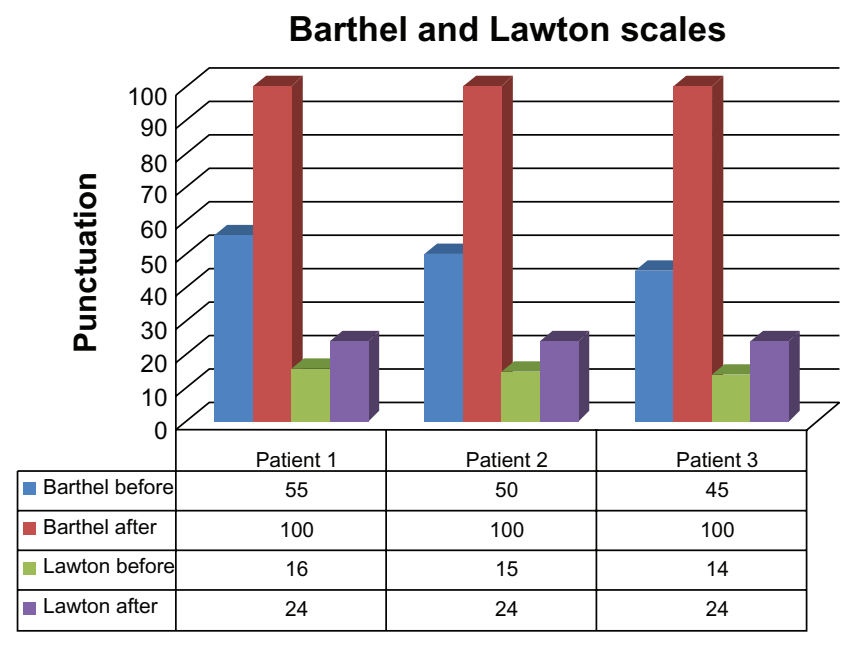

Figure 2 Analysis of the Barthel and Lawton scales before and after low-intensity laser therapy.

There are no similar studies presented in the current literature, and thus the results of the current study may not be directly compared to other work. In a meta-analysis of the use of LILT in patients with low back pain by Cochrane, ${ }^{31}$ laser treatment was beneficial in reducing pain unless patients were subjected to physical exercise as an adjunct treatment.

It is known that pain causes loss of function and decreased independence of the individual, often leading to reduced mobility and increased rates of depression. The present study shows that LILT can result in an improvement in patient independence, with an average gain of 50\% in the Barthel scale and 37.5\% in the Lawton scale, and all improved to the point where they gave themselves the highest scores possible for the scales used in the study. This indicates that LILT can be used in the future to decrease pain in patients following amputations.

This study's sample is small and no control group was used, which prevents any extrapolation of the results. The reported results should be seen as a stimulus for randomized studies with larger sample sizes to confirm the effectiveness of LILT in the treatment of chronic pain in patients with amputated limbs.

\section{Disclosure}

The authors report no conflicts of interest in this work.

\section{References}

1. Amputee Coalition of America [Website]. Available at: http://www. amputee-coalition.org. Accessed on December 29, 2011.

2. Jensen TS, Krebs B, Nielson J, Rasmussen P. Phantom limb, phantom pain and stump pain in amputees during the first 6 months following limb amputation. Pain. 1983;17(3):243-256.

3. Jensen TS, Krebs B, Nielson J, Rasmussen P. Immediate and long term phantom pain in amputees: Incidence, clinical characteristics and relationship to pre-amputation limb pain. Pain. 1985;21(3):267-278. 
4. Devor M, Seltzer Z. Pathophysiology of damaged nerves in relation to chronic pain. In: Wall PD, Melzack R, editors. Textbook of pain. Edinburgh, Scotland: Churchill Livingstone, 1999:129-164.

5. Nikolajsen L, Ilkjar S, Krøner K, Christensen JH, Jensen TS. The influence of preamputation pain on postamputation stump and phantom pain. Pain. 1997;72(3):393-405.

6. Nikolajsen L, Ilkjaer S, Jensen TS. Effect of preoperative extradural bupivacaine and morphine on stump sensation in lower limb amputees. Br J Anaesth. 1998;81(3):348-353.

7. Schley MT, Wilms P, Toepfner S, et al. Painful and nonpainful phantom and stump sensations in acute traumatic amputees. J Trauma. 2008;65(4):858-864.

8. Devers A, Galer BS. Topical lidocaine patch relieves a variety of neuropathic pain conditions: An open-label study. Clin J Pain. 2000;16(3):205-208.

9. Ramachandran VS, Rogers-Ramachandran D. Synaesthesia in phantom limbs induced with mirrors. Proc Biol Sci. 1996;263(1369):377-386.

10. Whipple RR, Unsell RS. Treatment of painful neuromas. Orthop Clin North Am. 1988;19(1):175-185.

11. Ducic I, Mesbahi AN, Attinger CE, Graw K. The role of peripheral nerve surgery in the treatment of chronic pain associated with amputation stumps. Plast Reconstr Surg. 2008;121(3):908-914.

12. Basford JR. Low-energy laser therapy: controversies and new research findings. Lasers Surgery Med. 1989;9(1):1-5.

13. Baxter GD, Bell AJ, Allen JM, Ravey J. Low-level laser therapy: Current clinical practice in Northern Ireland. Physiotherapy. 1991;77(3): 171-178.

14. Ohshiro T, Calderhead RG. Development of low reactive-level laser therapy and its present status. J Clin Laser Med Surg. 1991;9(4): 267-275.

15. Lyons RF, Abergel RP, White R, Dwyer RM, Castel JC, Uitto J. Biostimulation of wound healing in vivo by a helium-neon laser. Ann Plastic Surg. 1987;18(1):47-50.

16. Anders JJ, Borke RC, Woolery SK, Van de Merwe WP. Low power laser irradiation alters the rate of regeneration of the rat facial nerve. Lasers Surg Med. 1993;13(1):72-82.

17. Naeser MA, Hahn KA, Lieberman BE, Branco KF. Carpal tunnel syndrome pain treated with low-level laser and microamperes transcutaneous electric nerve stimulation: a controlled study. Arch Phys Med Rehabil. 2002;83(7):978-988.

18. Pinheiro AL, Cavalcanti ET, Pinheiro TI, Alves MJ, Manzi CT. Low-level laser therapy in the management of disorders of the maxillofacial region. J Clin Laser Med Surg. 1997;15(4):181-183.
19. Walker J. Relief from chronic pain by low power laser irradiation. Neurosci Lett. 1983;43(2-3):339-344.

20. Passarella S. He-Ne laser irradiation of isolated mitochondria. J Photochem Photobiol B. 1989;3:642-643.

21. Yamamoto H, Ozaki A, Iguchi N, Kinoshita S. Antinociceptive effects of laser irradiation of Hoku point in rats. Pain Clin. 1988;8:43-48.

22. Ailioaie C, Lupusoru-Ailioaie LM. Beneficial effects of laser therapy in the early stages of rheumatoid arthritis onset. Laser Ther. 1999;11(2):79-87.

23. Campaña V, Catsel A, Vidal AE, Juri H, Palma JA. Prostaglandin $\mathrm{E}_{2}$ in experimental arthritis of rats irradiated with He-Ne laser. J Clin Laser Med Surg. 1993;11(2):79-81.

24. Honmura A, Yanase M, Obata J, Haruki E. Therapeutic effect of Ga-Al-As diode laser on experimentally induced inflammation in rats. Lasers Surg Med. 1992;12(4):441-449.

25. Sakurai Y, Yamaguchi M, Abiko Y. Inhibitory effect of low-level laser irradiation on LPS-stimulated prostaglandin E2 production and cyclooxygenase-2 in human gingival fibroblasts. Eur J Oral Sci. 2000;108(1):29-34.

26. Shimizu N, Yamaguchi M, Goseki T, et al. Inhibition of prostaglandin E2 and interleukin1-beta production by low-power laser irradiation in stretched human periodontal ligament cells. J Dent Res. 1995;74(7):1382-1388.

27. Mahoney FI, Barthel DW. Functional evaluation: the Barthel Index. Md State Med J. 1965;14:61-65.

28. Lawton MP, Brody EM. Assessment of older people: Selfmaintaining and instrumental activities of daily living. Gerontologist. 1969;9(3):179-186.

29. Lam LK, Cheing GL. Effects of 904-nm low-level laser therapy in the management of lateral epicondylitis: a randomized controlled trial. Photomed Laser Surg. 2007;25(2):65-71.

30. Canadian Medical Association: Clinical practice guidelines for the care and treatment of breast cancer. Can Med Assoc J. 1998;158(Suppl 2):S1-S2.

31. Yousefi-Nooraie R, Schonstein E, Heidari K, et al. Low level laser therapy for nonspecific low-back pain. Cochrane Database Syst Rev. 2008;(2):CD005107.
International Journal of General Medicine

\section{Publish your work in this journal}

The International Journal of General Medicine is an international, peer-reviewed open-access journal that focuses on general and internal medicine, pathogenesis, epidemiology, diagnosis, monitoring and treatment protocols. The journal is characterized by the rapid reporting of reviews, original research and clinical studies across all disease areas.

\section{Dovepress}

A key focus is the elucidation of disease processes and management protocols resulting in improved outcomes for the patient.The manuscript management system is completely online and includes a very quick and fair peer-review system. Visit http://www.dovepress.com/ testimonials.php to read real quotes from published authors. 